\title{
Methamphetamine Self-Administration Elicits Sex-Related Changes in Postsynaptic Glutamate Transmission in the Prefrontal Cortex
}

\author{
(1)Jose Ignacio Pena-Bravo,, ${ }^{1}$ Rachel Penrod, ${ }^{1}$ Carmela M. Reichel, ${ }^{1}$ and ${ }^{\circledR}$ Antonieta Lavin ${ }^{1}$
}

https://doi.org/10.1523/ENEURO.0401-18.2018

${ }^{1}$ Department of Neuroscience, Medical University of South Carolina, Charleston, SC 29425

\begin{abstract}
Preclinical and clinical research has shown that females are more vulnerable to the rewarding effects of stimulants, and it has been proposed that estrogens may play a role in this enhanced sensitivity; however sex differences in methamphetamine (METH)-induced neuroplasticity have not been explored. To address this gap in knowledge, we recorded from the prelimbic area of the prefrontal cortex (PL-PFC) of male and female rats following long access METH self-administration (SA) and investigated the resulting long-term synaptic neuroadaptations. Males and females took similar amounts of METH during SA; however, female rats exhibit significant synaptic baseline differences when compared to males. Furthermore, females exhibited a significant increase in evoked excitatory currents. This increase in evoked glutamate was correlated with increases in NMDA currents and was not affected by application of a GluN2B selective blocker. We propose that METH SA selectively upregulates GluN2B-lacking NMDA receptors (NMDAR) in the PFC of female rats. Our results may provide a mechanistic explanation for the sex differences reported for METH addiction in females.
\end{abstract}

Key words: gluatamte; metampetamine; NMDA; prefrontal cortex; sex

\section{Significance Statement}

The rate of methamphetamine (METH) addiction is second only to heroin, and use trends are on the rise. Like other drugs of abuse, there are known sex differences in METH addiction; however, whether these differences result from sex differences in pharmacokinetics, neurophysiology, and/or drug-induced neuroplasticity has not been established. Here we assessed METH self-administration (SA)-induced neuroadaptations in synaptic physiology using electrophysiological measures in prefrontal cortical (PFC) brain slices of male and female rats. We are the first to report, to our knowledge, that cortical baseline and METHinduced synaptic responses are different between male and female rats. Our results may provide a mechanistic explanation for the sex differences reported for METH addiction in females and highlight the possibility that sex-specific treatment strategies may be required to address METH-induced neuroplasticity.

\section{Introduction}

Methamphetamine (METH) addiction is second only to heroin, and use trends are on the rise in North America (UNODC, 2017). Chronic METH use results in dysregulated cortical function and ensuing cognitive sequelae contributing to the chronic relapsing nature of METH

Received October 16, 2018; accepted December 20, 2018; First published January 10, 2019.

The authors do not have any conflict of interest to report. addiction (for review, see Bernheim et al., 2017). The underlying pathology of addiction and relapse clearly implicate changes in synaptic plasticity within the reward circuit as one of the fundamental mechanisms underlying this disorder (Luthi and Luscher, 2014). The prefrontal cortex (PFC) exerts top-down control over behavior and 
sends glutamatergic projections to the nucleus accumbens (among other areas) and dysfunction of the medial PFC ( $m P F C$ ) is credited with the loss of control over drug taking behavior (Goldstein and Volkow, 2011).

While considerable advancements have been made to understand the circuits underlying METH addiction, relapse, and cognitive dysfunction, very little is known about the synaptic mechanisms in play. Experimenter delivered METH (1 mg/kg, $7 \mathrm{~d}$ ) decreases calcium currents and excitatory transmission in the MPFC $4 \mathrm{~d}$ after drug treatment (González et al., 2016). Additionally, we have shown that long-access METH self-administration $(\mathrm{SA} ; 6 \mathrm{~h} / \mathrm{d})$ increases the proportion of burst firing pyramidal cells compared to tonic firing cells in mPFC (Parsegian et al., 2011); however, it was unknown whether this increased burst firing results from presynaptic and/or postsynaptic changes. In a recent study, we found that long-access METH SA decreases AMPA/NMDA ratio in pyramidal neurons of the mPFC, accompanied by an increase in NMDA currents and surface expression of the GluN2B subunit of the NMDA receptor (NMDAR; Mishra et al., 2017). Together, these results show that METH elicits multiple forms of long-term synaptic changes in the PFC, suggesting that altered synaptic function is one of the fundamental mechanisms affected by this drug.

While the aforementioned studies have all been conducted in male rats, there are known sex differences in METH SA behavior. Females are reported to acquire METH SA faster than males (Roth and Carroll, 2004), take more drug (Roth and Carroll, 2004; Reichel et al., 2012; Bernheim et al., 2017), and have greater motivation to seek the drug (Roth and Carroll, 2004; Cox et al., 2013, 2017). Male and female rats typically reinstate to METH cues in a similar manner (Bernheim et al., 2017; Cox et al., 2017), but females reinstate to a greater magnitude than males in response to priming injections of the drug (Reichel et al., 2012; Cox et al., 2013). Furthermore, in an incubation of METH craving model, females seek drug to a greater degree than males following $14 \mathrm{~d}$ of abstinence (Ruda-Kucerova et al., 2015). However, following a period of voluntary abstinence, male and female rats equivalently abstain for METH when given a choice between drug and food (Venniro et al., 2017). Whether these differences result from sex differences in METH pharmacokinetics (Milesi-Hallé et al., 2007, 2015) or METH-induced neuroplasticity has not been established.

To address this question, we recorded from the prelimbic area of the PFC (PL-PFC) of male and female rats following long access METH SA. We report that males and females took similar amounts of METH during SA;

This work was supported by National Institutes of Health/National Institute on Drug Abuse Grants R01DA033049 (to C.M.R.), T32 DA 007288-21 (to J.I.P.B.), and 1R21DA045889-01A1 (to A.L.).

Correspondence should be addressed to Antonieta Lavin at lavina@ musc.edu.

https://doi.org/10.1523/ENEURO.0401-18.2018

Copyright (C) 2019 Ignacio Pena-Bravo et al.

This is an open-access article distributed under the terms of the Creative Commons Attribution 4.0 International license, which permits unrestricted use, distribution and reproduction in any medium provided that the original work is properly attributed. however, female rats exhibit synaptic differences when compared to males and METH SA elicited significant changes in NMDA kinetics in female rats. Furthermore, we found a significant increase in evoked glutamate in females, that was correlated with increases in GluN2Blacking NMDA currents. These results provide important insight into a possible mechanism underlying the increased susceptibility to METH addiction in females and highlight a possible sex-specific plasticity for future pharmacotherapeutic targeting.

\section{Materials and Methods}

\section{Animal housing}

Age-matched Sprague Dawley male (225-250 g) and female $(200-225 \mathrm{~g})$ rats $(n=16$; eight males and eight females) were obtained from Charles River and individually housed on $12 / 12 \mathrm{~h}$ reversed light/dark cycle with free access to water and food, until the beginning of SA (see Catheter implantation surgery). During the SA sessions, rats were provided $15-30 \mathrm{~g}$ of chow per day with free access to drinking water in their respective home cage. All procedures were conducted in accordance with the Guide for the Care and Use of Laboratory Rats (Institute of Laboratory Animal Resources on Life Sciences, National Research Council, 2011) and were approved by the Institutional Animal Care and Use Committee of the University.

\section{Catheter implantation surgery}

Rats were anesthetized with intraperitoneal injections of ketamine (66 mg/kg; Vedco Inc.), xylazine $(1.3 \mathrm{mg} / \mathrm{kg}$; Lloyd Laboratories), and equithesin $(0.5 \mathrm{ml} / \mathrm{kg} ; 4 \mathrm{mg} / \mathrm{kg}$ sodium pentobarbital, $17 \mathrm{mg} / \mathrm{kg}$ chloral hydrate, and 21.3 $\mathrm{mg} / \mathrm{kg}$ magnesium sulfate heptahydrate dissolved in $44 \%$ propylene glycol and $10 \%$ ethanol solution). Ketorolac (2.0 mg/kg, i.p.; Sigma) was given just before surgery as an analgesic. One end of a SILASTIC catheter was inserted $33 \mathrm{~mm}$ into the external right jugular and secured with 4.0 silk sutures. The other end ran subcutaneously and exited from a small incision just below the scapula. That end was attached to an infusion harness (Instech Solomon) that provided access to an external port for intravenous drug delivery. Following that surgical procedure, rats were given a subcutaneous injection of an antibiotic solution cefazolin $(10 \mathrm{mg} / 0.1 \mathrm{ml}$; Schein Pharmaceuticals) and were allowed to recover for $5 \mathrm{~d}$.

\section{METH SA}

SA occurred in chambers $(30 \times 20 \times 20 \mathrm{~cm}$, Med Associates) housed inside sound-attenuating cubicles that were fitted with a fan, metal arm, and spring leash attached to a swivel (Instech); two retractable levers; two stimulus lights; a speaker for tone delivery; and a house light. Tygon tubing extended through the leash and connected to a $10-\mathrm{ml}$ syringe mounted on an infusion pump outside the cubicle. After $5 \mathrm{~d}$ of recovery, rats were assigned to METH or saline control groups. METH hydrochloride (Sigma), dissolved in sterile saline, was administered daily during 6-h sessions for $14 \mathrm{~d}$. Control animals self-administered saline. The house light signaled the beginning of a session and remained on throughout the 
session. A response on the active lever resulted in a 2-s infusion of METH $(0.05 \mathrm{mg} / \mathrm{kg}$ per infusion) or saline and presentation of a stimulus complex that consisted of a 5-s tone $(78 \mathrm{~dB}, 4.5 \mathrm{kHz})$ and a white stimulus light over the active lever, followed by a 20-s time out. Responses during the time out and on the inactive lever were recorded, but they had no scheduled consequences. Following SA, rats were placed on home cage abstinence for 9-14 $d$, then they were killed for end point measures of electrophysiology.

\section{Brain slice preparation}

Rats were deeply anesthetized using isoflurane (Minrad Inc.) and the brain was quickly isolated following decapitation. Coronal slices containing mPFC (300 $\mu \mathrm{m})$ were cut in ice-cold high-sucrose solution containing: $200 \mathrm{mM}$ sucrose, $1.9 \mathrm{mM} \mathrm{KCl}, 1.2 \mathrm{mM} \mathrm{Na}_{2} \mathrm{HPO}_{4}, 33 \mathrm{mM} \mathrm{NaHCO}_{3}, 6$ $\mathrm{mM} \mathrm{MgCl}_{2}, 0.5 \mathrm{mM} \mathrm{CaCl}_{2}, 10 \mathrm{mM} \mathrm{D-glucose,} \mathrm{and} 0.4 \mathrm{mM}$ ascorbic acid using a Leica VT $1200 \mathrm{~S}$ vibratome. Slices were incubated at $31^{\circ} \mathrm{C}$ for at least $1 \mathrm{~h}$ before recordings; the incubation medium contained: $120 \mathrm{mM} \mathrm{NaCl}, 2.5 \mathrm{mM}$ $\mathrm{KCl}, 1.25 \mathrm{mM} \mathrm{NaH}_{2} \mathrm{PO}_{4}, 25 \mathrm{mM} \mathrm{NaHCO}_{3}, 4 \mathrm{mM} \mathrm{MgCl}_{2}, 1$ $\mathrm{mM} \mathrm{CaCl}_{2}, 10 \mathrm{mM}$ D-glucose, and $0.4 \mathrm{mM}$ ascorbic acid, aerated with $5 \% \quad \mathrm{CO}_{2} / 95 \% \quad \mathrm{O}_{2}$. Following incubation, slices were transferred to a submerged chamber and superfused at room temperature with oxygenated artificial CSF (aCSF): $126 \mathrm{mM} \mathrm{NaCl}, 2.5 \mathrm{mM} \mathrm{KCl}, 1.4 \mathrm{mM}$ $\mathrm{NaH}_{2} \mathrm{PO}_{4}, 25 \mathrm{mM} \mathrm{NaHCO}, 2.0 \mathrm{mM} \mathrm{CaCl}$, $1.3 \mathrm{mM}$ $\mathrm{MgCl}_{2}, 10 \mathrm{mM}$ D-glucose, and $0.4 \mathrm{mM}$ ascorbic acid.

\section{Voltage clamp recordings}

Electrophysiological recordings were obtained with a Multiclamp 700B amplifier (Molecular Devices). Signals were low-pass filtered at $3 \mathrm{kHz}$ and digitized at $10 \mathrm{kHz}$. Data were stored on a PC for off-line analysis. Data acquisition was performed using Axograph-X software (J. Clements). Analysis of spontaneous EPSCs (sEPSCs) and evoked EPSCs (eEPSCs) peak amplitude data were done in Mini Analysis (v6.0.7; Synaptosoft). For voltage-clamp recordings, electrodes (2.5-3.5 $\mathrm{M} \Omega$ resistance in situ) were filled with a solution containing: $130 \mathrm{mM} \mathrm{CsCl}, 10$ mM HEPES, 2 mM MgCl $2,0.5$ mM EGTA, 2 mM Na ${ }_{2}$ ATP, $0.3 \mathrm{mM}$ Na-GTP, $2 \mathrm{mM}$ QX-314, $10 \mathrm{mM}$ phosphocreatine, and $285 \mathrm{mOsmol}$. Briefly, membrane potential was held at $-70 \mathrm{mV}$ and GABA-mediated events were pharmacologically isolated by adding picrotoxin $(50 \mu \mathrm{M})$ to the bath. Series resistance (Rs) was continuously monitored by applying a small hyperpolarizing voltage step $(-5 \mathrm{mV}, 50$ $\mathrm{ms})$, and recordings that exhibit changes in baseline Rs > $30 \%$ were discarded. sEPSC recordings consisted of five sweeps/10-s-long recordings that were analyzed for amplitude and frequency of detected events. After recordings sEPSCs, the membrane potential was shifted to +40 $\mathrm{mV}$ and $10 \mu \mathrm{M}$ CNQX (non-NMDAR blocker) was added for at least $5 \mathrm{~min}$ to isolate NMDA-mediated responses. Eight to 10 isolated NMDA responses were recorded. The AMPA current was obtained by digital subtraction $\left(I_{\text {Total }}-\right.$ $I_{\text {NMDA}}$ ), and the ratio was calculated with the following formula: I AMPA $/ I_{\text {Total }}-I_{\text {AMPA. The cells recorded did not }}$ differ statistically in their mean capacitance (saline females: $0.52 \pm 0.39 \mathrm{pF}$; METH females: $0.84 \pm 1.4 \mathrm{pF}$; saline males: $0.32 \pm 0.28 \mathrm{pF}$; METH males: $0.89 \pm 0.35$ $\mathrm{pF}$, Axograph). After recording AMPA/NMDA ratio, the membrane potential was clamped at $-40 \mathrm{mV}$, to alleviate the $\mathrm{Mg}+$ blockade, and 8-10 baseline evoked potentials were recorded before adding the GluN2B blocker Ro256981 (1 $\mu \mathrm{m}$; Tocris) and after 5 min evoked potentials recordings were resumed for 8-10 events. For sEPSC and eEPSC kinetics, we used Minianalysis, and the parameters for detection were: threshold: five times the root mean square of noise; period to search a local maximum: $7000 \mu \mathrm{s}$; time before a peak: 25,000 $\mu \mathrm{s}$; period to search a decay: $150,000 \mu \mathrm{s}$; function of peak to find a decay time: 0.10; and period to average a baseline: 2000 $\mu \mathrm{s}$. All detected events per cell were used to obtain average rise $(\mathrm{ms})$, decay $(\mathrm{ms})$, and area $(\mathrm{pA} * \mathrm{mV})$ for all experimental groups. All recordings were obtained from pyramidal neurons in Layer $\mathrm{V}$ or $\mathrm{VI}$ of the prelimbic mPFC which were identified using infrared-differential interference contrast optics and video microscopy. We recorded four rats per group. All recordings were performed at the same time of the day and the experimenter was blind to the animal treatment.

To assess whether METH SA elicited changes in release probability or the number of releases sites, we assessed the coefficient of variation (CV) of sEPSCs (Choi and Lovinger, 1997).

\section{Data analysis \\ METH SA}

Lever presses and drug intake were the primary dependent measures during SA. Independent variables included group (METH and saline), sex (males and females), lever (active and inactive), and day (14 d of SA). Data were analyzed with ANOVA. Lever presses were analyzed with a three-way ANOVA including group, lever, and day as variables separately for males and females. A significant three-way interaction was deconstructed with follow-up two-way ANOVAs to compare lever responding at the different levels of the group independent variable. Males and females were directly compared on METH intake with a two-way ANOVA with sex and day as the independent variables. Sidak's Holmes adjustments were used to control for family-wise error. All data were analyzed and plotted using GraphPad Prism version 7.0 (GraphPad Software, Inc).

\section{Electrophysiology}

Amplitude, frequency, rise time area under the curve and decay time (sEPSCs and eEPSCs) were the dependent measures for most electrophysiology experiments. Independent variables of sex (males and females) and drug condition (METH and saline) were examined using a $2 \times 2$ between subjects ANOVA, and interactions were followed by Tukey's post hoc comparisons for between subjects variable and Sidak's Holmes for within subject variables. Additionally, following the guidance of our statisticians in the Department of Biostatistics, Epidemiology, and Research Design at Medical University of South Carolina, we conducted pairwise contrasts since ANOVA can only test one hypothesis (the global test) and may miss some meaningful pairwise differences between groups. 

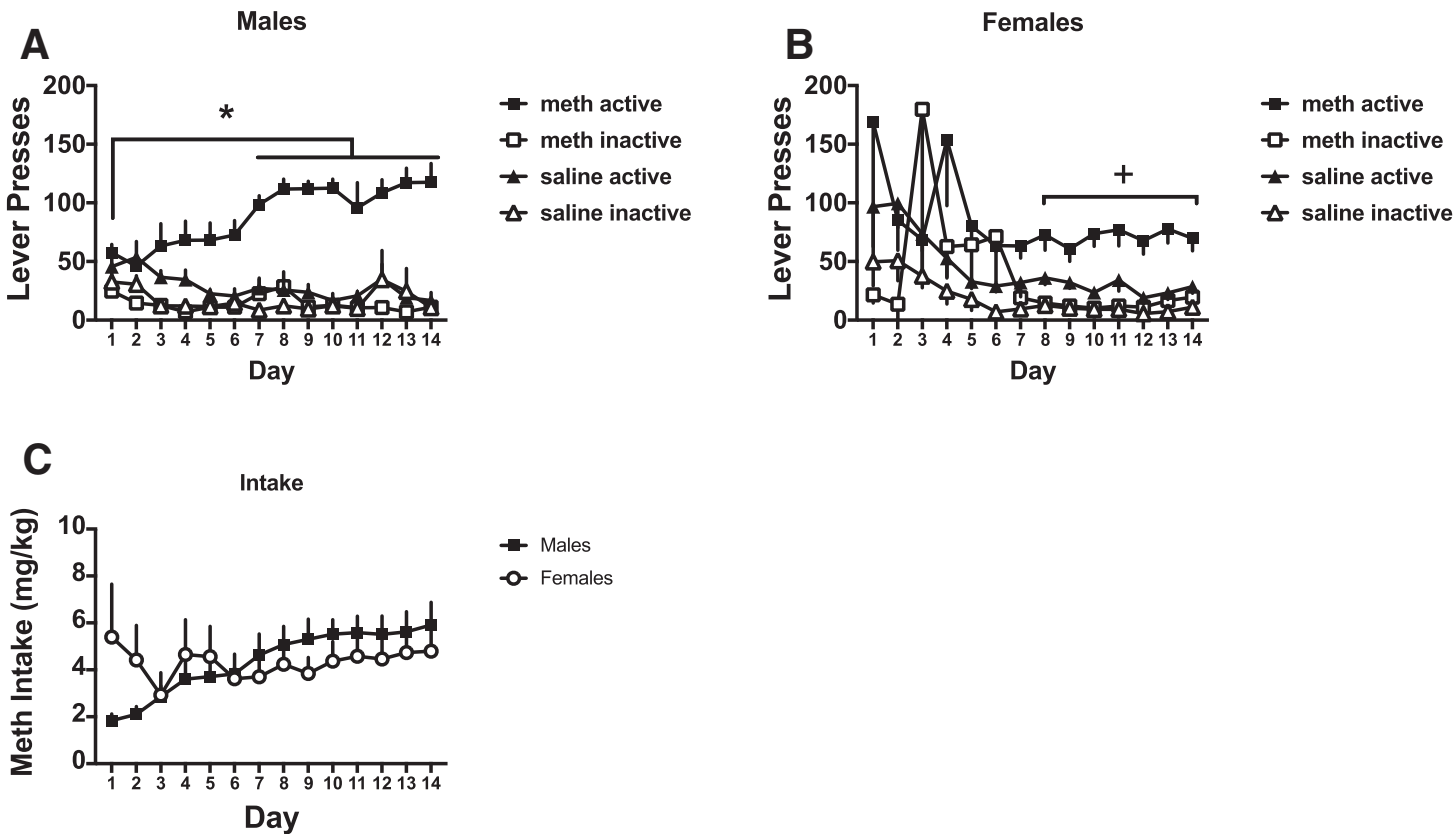

Figure 1. Lever presses and METH intake for male and female rats. $\boldsymbol{A}$, Male rats escalated active lever presses over time and responded more on the active lever relative to saline self-administering rats and the inactive lever. $\boldsymbol{B}$, Female rats pressed the active lever more relative to saline self-administering rats and the inactive lever during the last week of SA. $\boldsymbol{C}$, Male and female rats took similar amount of METH throughout SA; *significantly different from day 1 of SA $(p<0.05)$; +, significantly different from inactive lever responding. All the figures represent average \pm SEM.

sEPSCs and eEPSCs were analyzed using Minianalysis software by Synaptosoft version 6.0.7. The threshold for noise was selected as five times the RMS noise, measured in a $125-\mathrm{ms}$ episode. CV was calculated as $\delta / \mu$, where $\delta$ is the Standard Deviation of the peak sEPSC amplitude and $\mu$ is the mean SEPSC amplitude. All data were analyzed and plotted using GraphPad Prism version 7.0 (GraphPad Software, Inc).

\section{Results}

\section{Metamphetamine Self-Administration}

During the SA period, we assessed active and inactive lever responding in METH and saline-trained rats across $14 \mathrm{~d}$ of SA ( $n=4$ /group). In male rats (Fig. $1 A$ ), there was a significant three-way interaction between group (METH vs saline), lever (active vs inactive), and day $\left(F_{(13,13)}=\right.$ 3.02, $p<0.05$; Fig. 1A). Lever responses over day were analyzed at the two levels of the independent variable group. For METH rats there was a lever by day interaction (two-way ANOVA, $F_{(13,78)}=5.81, p<0.05$ ) with post hoc comparisons showing that active lever responding increased on days $8-14$ relative to day 1 (Sidak-Holm post hoc, $p<0.05$ ). Further responding on the active lever was significantly above the inactive lever on all $14 \mathrm{~d}$ (SidakHolm post hoc, $p<0.05$ ). For saline rats, there was no significant lever by day interaction, but there was a significant main effect of day $\left(F_{(13,78)}=3.12, p<0.05\right)$. Post hoc comparisons over day did not reveal any significant differences between days.

In female rats (Fig. 1B), the three-way ANOVA was not significant, nor were the resulting two-way ANOVAs. There were however, main effects of group $\left(F_{(13,13)}=\right.$
14.53, $p<0.05)$, lever $\left(F_{(13,13)}=21.03, p<0.05\right)$, and day $\left(F_{(13,13)}=2.28, p<0.05\right)$. To determine whether METH females acquired lever discrimination, we conducted a two-way ANOVA with lever and day as the independent variables. There was a significant main effect of lever $\left(F_{(1,6)}=23.89, p<0.05\right)$ with active lever responses being higher than inactive responses.

The amount of METH taken by male and female rats over the $14 \mathrm{~d}$ of SA did not differ (Fig. 1C). There was a significant interaction between sex and day $\left(F_{(13,78)}=2.2\right.$, $p<0.017$ ), but post hoc comparisons did not reveal significant group differences. The main effect of day was significant $\left(F_{(13,78)}=2.27, p<0.013\right)$, but the main effect of sex was not significant.

\section{Synaptic activity}

To determine whether a history of METH SA produced sex-specific forms of synaptic plasticity, we examined changes in synaptic activity in deep layers (Layer V/VI) pyramidal neurons in the prelimbic PFC. Following $14 \mathrm{~d}$ of METH SA and 9-14 d of withdrawal, we assessed spontaneous and evoked synaptic activity (amplitude, frequency, kinetics) with sex and treatment (METH vs saline) as factors.

Females had significantly lower SEPSC amplitude relative to males, indicated by a main effect of sex $\left(F_{(1,59)}=\right.$ 7.99, $p=0.006$; Fig. $2 A$ ). There was no significant interaction or main effect of drug treatment. There we no differences in frequency of sEPSCs (Fig. 2B). Representative traces are depicted in Figure $2 C-F$. Measures of the sEPSCs CV confirm that METH SA did not elicit changes in probability of release of glutamate (female saline: $0.89 \pm$ 
A

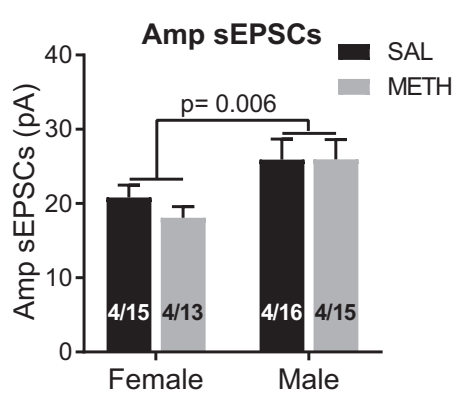

C

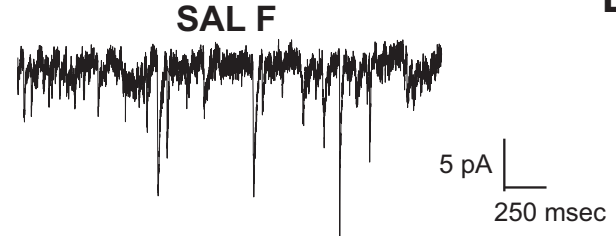

E

METH F

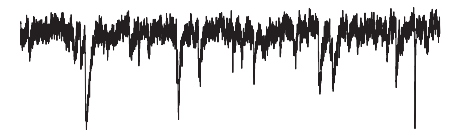

G
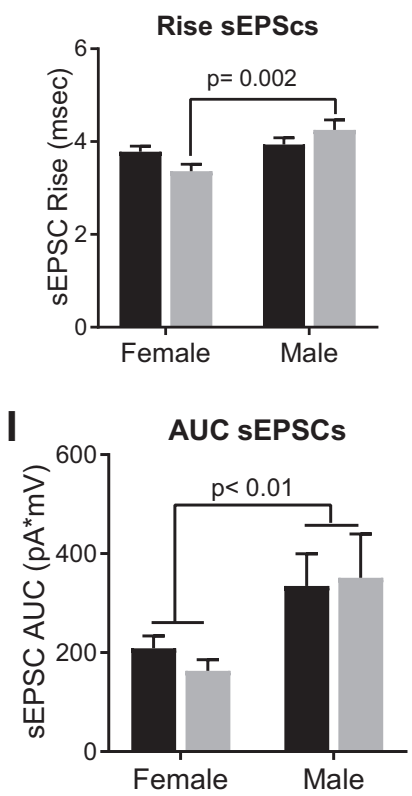

B

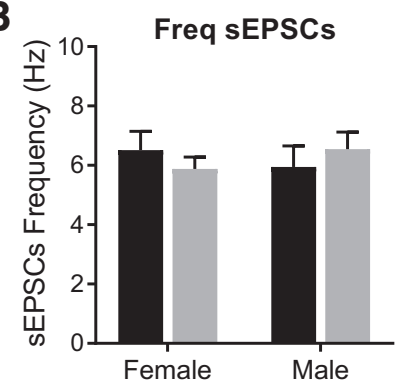

D

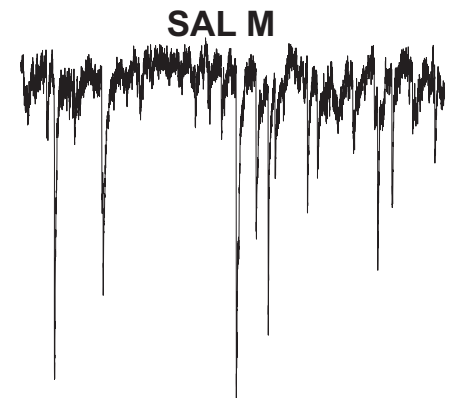

F

METH M

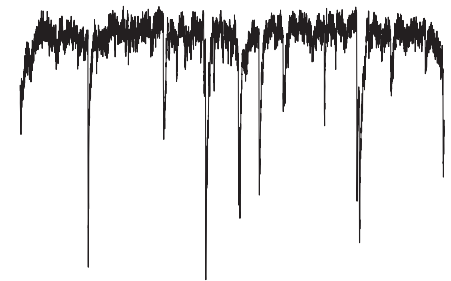

H

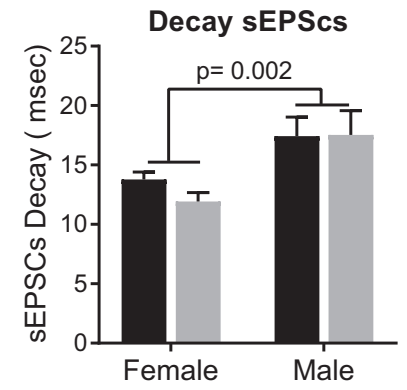

J

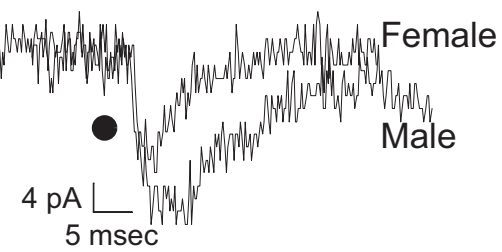

Figure 2. Baseline sex differences in spontaneous excitatory activity. $\boldsymbol{A}$, Female rats exhibited significantly lower amplitude of sEPSCs when compared to male rats; but $\boldsymbol{B}$ shows there were no significant differences in the frequency of sEPSCs between males or females and self-administered METH or saline. $\boldsymbol{C}-\boldsymbol{F}$, Representative traces of sEPSCs in saline females (SAL F), saline males (SAL M), METH females, and METH male rats. $\boldsymbol{G}$, Female rats had a significantly faster rise of sEPSCs relative to males and $(\boldsymbol{H})$ female rats exhibited 
continued

a significant faster decay of sEPSCs. I, Relative to males, female rats had a significant decrease in the AUC of sEPSCs. $\boldsymbol{J}$, Representative traces illustrating sex differences in kinetics of sEPSCs. The numbers in the bars represent the number of rats/number of cells.

0.11; female METH: $0.85 \pm 0.14$; male saline: $0.83 \pm 0.05$; male METH: $0.91 \pm 0.01$; data not shown). Male rats had significantly slower sEPSC rise and decay, and a larger area under the curve (AUC), compared to females. Specifically, for the rise of sEPSCs, there was a significant interaction between sex and treatment $\left(F_{(1,59)}=5.0, p=\right.$ 0.002 ; Fig. 2G). Female METH rats have a significantly faster rise than male METH rats (Tukey's, $p=0.002$ ). On the decay of sEPSCs, there was a main effect of sex $\left(F_{(1,59)}=10.34, p=0.002\right.$; Fig. $\left.2 H\right)$. The interaction and main effect of drug were not significant. Similarly for the AUC, there was a main effect of $\operatorname{sex}\left(F_{(1,59)}=7.0, p=\right.$ 0.01 ; Fig. 2l) with females exhibiting reduced AUC, consistent with the faster rise and decay times. The interaction and main effect of drug were not significant. Figure $2 \mathrm{~J}$ depicts representative traces from male and female rats.

In summary, female rats exhibit significant decreases in basal glutamatergic excitatory strength when compared to males.

\section{Evoked EPSCs}

To investigate changes in evoked glutamate release, we assessed eEPSCs recorded at $+40 \mathrm{mV}$. We used twoway ANOVA with sex and treatment (saline or METH SA) as factors. Analyzing the amplitude of eEPSCs, we found a significant sex $\times$ treatment interaction $\left(F_{(1,38)}=6.5, p=\right.$ 0.01 ; Fig. $3 A$ ), and post hoc Tukey's analysis show that female METH rats have significantly larger eEPSC amplitude $(p=0.03)$ compared to female SAL. Figure $3 B$ depicts representative traces of all groups. When analyzing the decay of eEPSCs, we found a significant sex by treatment interaction $\left(F_{(1,38)}=5.5, p=0.02\right.$; Fig. $\left.3 C\right)$; however, post hoc examinations were not significant. We conducted planned contrasts (see Materials and Methods, Data analysis) and determined that male METH rats had significantly faster decay than saline counterparts (planned contrast, $t_{(20)}=2.3, p=0.03$ ). Similarly, we found a significant interaction when analyzing AUC $\left(F_{(1,38)}=5.5, p=0.02\right.$; Fig. $\left.3 D\right)$ and planned contrast showed a significant increase in the AUC of METH females versus SAL females $(p=0.04)$. Analysis of the CV did not show significant differences (saline females: $0.16 \pm$ 0.05; METH females: $0.20 \pm 0.15$; saline males: $0.18 \pm 0.04$; METH males: $0.26 \pm 0.19$; data not shown). In summary, METH SA significantly increased evoked glutamate in female rats and accelerated decay in males suggesting that METH SA increases NMDA currents in females without altering the kinetics of the NMDAR, whereas in males, METH SA affects NMDAR kinetics.

\section{GluN2B NMDAR blocker}

In an effort to investigate the mechanisms mediating the effects of METH on eEPSCs, we assessed the role of the NMDA GluN2B subunit using Ro256981, a subunit- specific antagonist. We used repeated measures ANOVA with treatment (saline or METH SA) and test drug (baseline and Ro256981) as factors. We analyzed male and female data as separate ANOVAs due to the notable sex differences in sEPSCs and eEPSCs described before. In female rats (Fig. 4A), METH increased the amplitude of the NMDA currents relative to saline (main effect treatment; $F_{(1,16)}=$ 6.27, $p=0.02$ ) and Ro256981 reduced NMDA current amplitude relative to baseline (main effect test drug; $F_{(1,16)}=23.2, p=0.0002$ ). In male rats (Fig. 4B), Ro256981 decreased the amplitude of NMDA currents (main effect of test drug; $F_{(1,18)}=40.5, p=0.0001$ ), but there were no differences between METH and saline.

We also tested the effects of the GluN2B blocker on the kinetics of the NMDA currents. Ro256981 did not affect decay of NMDA currents in female rats (Fig. 4C), but interestingly, in male rats, Ro256981 significantly decreased NMDA current decay (main effect test drug, $F_{(1,18)}=5.0, p=0.038$; Fig. $\left.4 D\right)$.

Planned contrasts show that the GluN2B blocker decreased the AUC in female saline rats relative to baseline animals (planned contrast, $t_{(9)}=3.67, p=0.05$; Fig. $4 E$ ). Ro256981 was without an effect in METH females. In male rats, Ro256981 significantly decreased the AUC (main effect test drug; $\left.F_{(1,18)}=17.16, p=0.0005\right)$ regardless of METH or saline SA.

These results suggest that the METH SA-dependent female-specific increase in the amplitude of NMDA currents was not blocked by Ro256981. Furthermore, analysis of the kinetic data shows that only in female saline and males (SAL and METH) NMDA current decay was decreased by Ro256981. In summary, data suggest that the METH-mediated increase in the amplitude of eEPSCs in females was mediated by increases in GluN2B-lacking NMDA currents and confirm our previous report that METH SA elicits an increase in GluN2B-containing NMDAR in male rats.

\section{Discussion}

To the best of our knowledge, this is the first report of sex differences in PFC synaptic activity in drug naïve males and females and those that have undergone METH SA. In this study, we found several sex differences: (1) female rats exhibit significantly lower basal amplitude of sEPSCs and faster kinetics than male rats, however, METH does not alter these measures in females or males; (2) METH SA increases the amplitude of eEPSCs in females; and (3) the GluN2B blocker Ro256981 significantly decreased the NMDA currents in males but did not block the METH-mediated increase in NMDA currents observed in female rats.

Females are reported to acquire METH SA faster than males (Roth and Carroll, 2004), take more drug (Roth and Carroll, 2004; Reichel et al., 2012; Bernheim et al., 2017), and have greater motivation to seek the drug (Roth and 
A

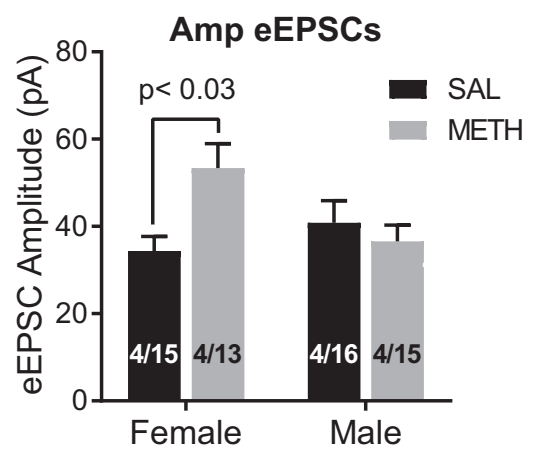

C

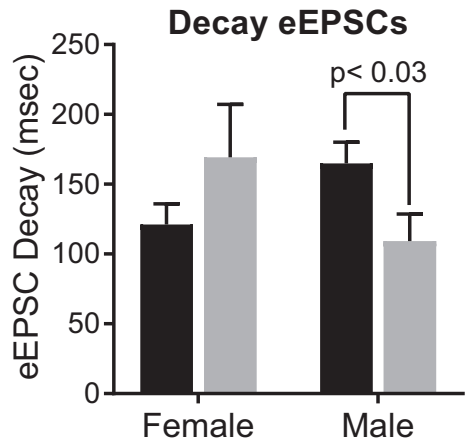

E
B

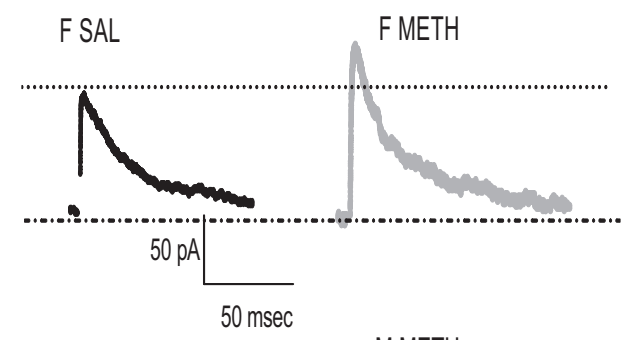

M SAL

M METH

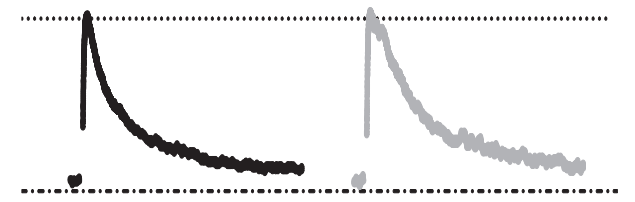

D

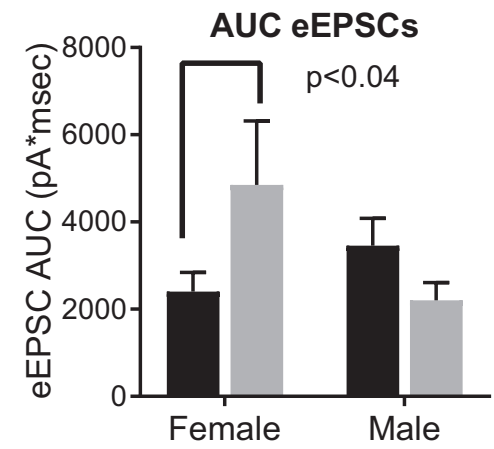

Males

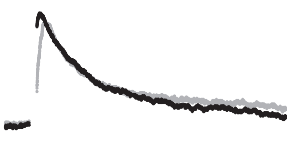

$$
50 \mathrm{pA} \frac{}{50 \mathrm{msec}}
$$

Figure 3. Effects of METH SA on eEPSCs. A, Female rats that self-administered METH had increased eEPSCs amplitude than saline control females; whereas there were no differences in males. $\boldsymbol{B}$, Representative traces of eESPC's amplitude. $\boldsymbol{C}$, When analyzing the decay of eEPSCs, we found a significant interaction. In females the decay was not significantly different but in males, METH SA rats show a significantly faster decay than SAL counterparts ( $t$ test, $p=0.01$ ). $\boldsymbol{D}$. Analysis of the AUC also shows a significant interaction and a significant increase in the AUC of female METH SA rats. $\boldsymbol{E}$, Representative traces showing the kinetics of eEPSCs. Each trace is the average of 10 events.

Carroll, 2004; Cox et al., 2013, 2017). Here, we used a METH SA protocol in which rats were given access to the drug for $6 \mathrm{~h}$ over 14 consecutive days. We do not report sex differences in drug intake, which is consistent with other studies using similar protocols (Johansen and McFadden, 2017; Venniro et al., 2017). However, female rats appear to take more drug on the first day of SA. Although this effect was not significant on a post hoc analysis, it is interesting to note that this day difference is consistent with reports that females acquire METH SA faster than males and take more drug than males (Roth and Carroll, 2004; Reichel et al., 2012; Bernheim et al., 2017). It is possible that enhanced METH intake during the 6-h session on day 1 rendered females more vulnerable to changes in PFC synaptic physiology discussed below. The overall lack of sex differences in drug intake render our sex differences in synaptic physiology particularly interesting because our behavioral output and drug exposure are equivalent yet the underlying neurophysiology are different. As such, we have identified a "convergent" 
Female

A

Amp NMDA Currents

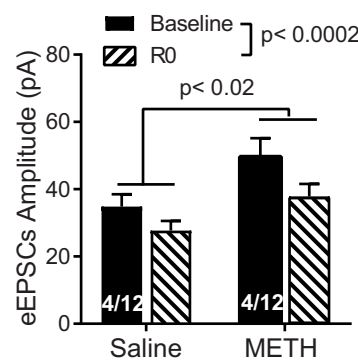

C

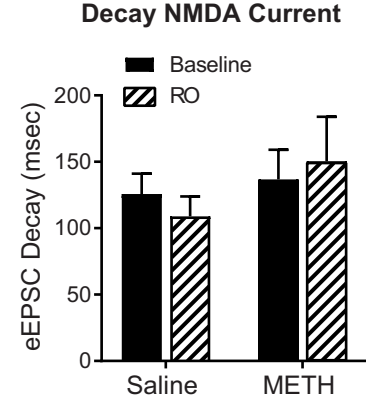

E

AUC NMDA Current

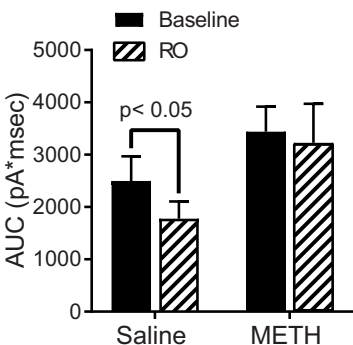

G

M SAL

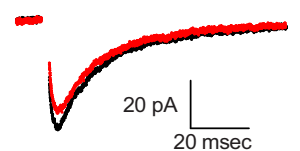

M METH

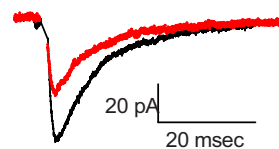

\section{Male}

B

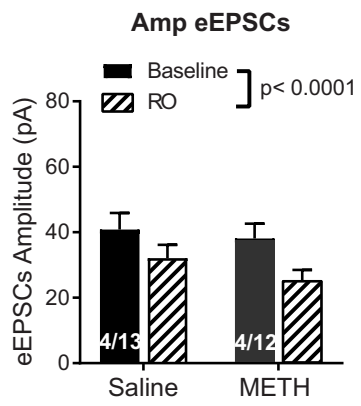

D

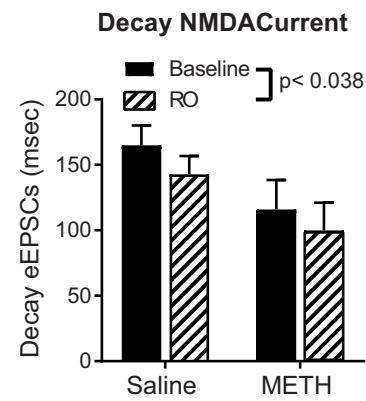

F

AUC NMDA Current

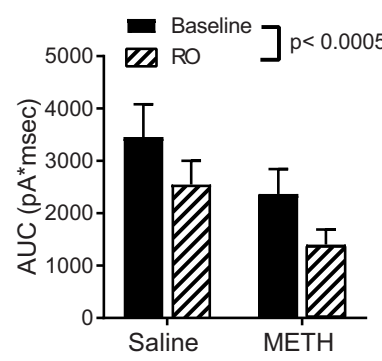

F SAL

F METH

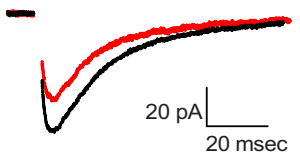

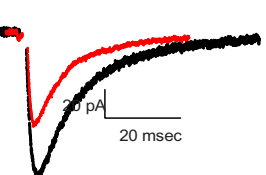

Figure 4. Effects of the GluN2B blocker. $\boldsymbol{A}$, Experiments performed in female rats show a main effect of treatment (SAL vs METH SA) and Ro256981 elicited a significant decrease in the NMDA current amplitude. $\boldsymbol{B}$, In male subjects, Ro256981 decreased the amplitude of NMDA currents, but there were no effects of treatment. $\boldsymbol{C}$, The GluN2B blocker did not affected the decay of the NMDA currents in females $\boldsymbol{D}$, In male rats, Ro256981 significantly decreased the decay of NMDA currents. $\boldsymbol{E}$, The GluN2B blocker showed a trend for decreasing the AUC in saline female rats. $\boldsymbol{F}$, In male rats, Ro256981 significantly decreased the AUC. G, Representative traces of the effects of Ro256981. Traces in black = baseline, traces in red = Ro256981. Each trace is the average of 10 events. Note the differences in scale.

sex difference in which behavioral endpoints are similar yet the underlying neurobiology is different (Becker and Koob, 2016).

\section{Baseline sex differences}

to investigate sex differences in synaptic glutamatergic function, we explored the characteristic of SEPSCs and eEPSCs. Our results show that there are sex differences in baseline sEPSCs in the PFC, with female rats possibly exhibiting decreases in postsynaptic glutamate receptors and in excitatory strength. It is accepted that changes in amplitude of SEPSCs are associated with differences in the levels of postsynaptic receptors and/or changes in the dynamics of the receptors (Engelman and MacDermott, 2004; Costa et al., 2017) and changes in the kinetics of sEPSC events can be indicative of alterations in receptor 
subunit composition and their interactions with auxiliary subunits as well as alternative RNA splicing and posttranslational modifications (Dingledine et al., 1999; Tomita, 2010; Granger et al., 2011; Stincic and Frerking, 2015). Our data show that female rats exhibit significant decreases in both parameters (i.e., amplitude and kinetics). Furthermore, since changes in SEPSC's AUC are thought to represent the net charge transfer during an ionotropic glutamate receptor-mediated event, our results suggests that female animals have decreases in basal glutamatergic excitatory strength when compared to males (Keller et al.,1991).

To our knowledge, there have not been reports addressing basal sex differences in glutamate receptors or synaptic activity of the PFC, so the mechanisms underlying the differences in synaptic physiology are unknown.

\section{Sex differences and effects of METH treatment on synaptic glutamatergic activity}

METH SA selectively increased the amplitude of eEPSCs in female rats. This result is supported by the significant increases found in the eEPSCs AUC in female rats. The AUC is thought to represent the net charge transfer, with increases indicating greater depolarization.

We have previously reported that METH SA increased GluN2B-containing NMDAR in males (Mishra et al., 2017). Here, we report again that METH SA elicits a significant reduction in the eEPSC decay in males compared to saline controls. METH-SA males show in average a decay of $120 \mathrm{~ms}$ (Fig. $3 \mathrm{C}$ ) that it is closer to the typical decay reported for GluN1/2A NMDAR ( 40-50 ms; Monyer et al., 1992; Vicini et al., 1998; Wyllie et al., 1998; Yuan et al., 2009), rather than average decay reported for GluN1/2B NMDAR (300-400 ms); however: (1) since the kinetics of NMDAR have been characterized in nonneuronal expression systems, it is highly likely that the decay times recorded in pyramidal neurons will be very different, particularly given the potential for intracellular regulation of receptor kinetics; (2) since the NMDA currents vary widely across different types of neurons; and (3) since voltage clamp cannot clamp voltage along the neuron processes, and thus altered kinetics are expected, we propose that METH SA males exhibit a GluN1/2B NMDAR composition, replicating our previous results. Furthermore, we previously confirmed the subunit composition of NMDAR in METH SA males via tissue biotinylation and surface-protein expression.

In order to investigate whether METH SA increased GluN2B-containing NMDAR in females, we repeated those experiments. Interestingly, we found that the METH SA-dependent female-specific increase in amplitude of eEPSCs was not blocked by Ro256981, and analysis of the NMDA current kinetics shows that, in contrast to males, the GluN2B blocker did not affect the kinetics of NMDA currents in METH SA females.

While the mechanisms underlying METH-mediated increases in GluN2B-containing NMDARs are unknown, recently Li et al. (2017) published a report suggesting that in dopamine (DA) cells of the midbrain, amphetamine and METH either stimulate a population of extrasynaptic
GluN2B-containing NMDARs or that it causes GluN2Bcontaining receptors to move laterally into the synapse. While further investigations will be needed to test this hypothesis, it is possible a similar mechanism regulates the increases in GluN2B-containing NMDARs in the PFC of males following METH SA. However, this hypothesis does not address the differences in METH-mediated effects between males and females. Further investigations examining NMDAR subunit composition, and their contributions to sex differences are needed. Interestingly, in male rats, we failed to detect a significant increase in sEPSC frequency following METH SA, in contrast to our previous findings (Mishra et al., 2017). We believe this difference is likely dependent on the amount of METH intake, as that was a critical difference between the two studies. It is possible that with longer METH SA experience ( 21 vs $14 \mathrm{~d}$ ), this effect would be observed. It is of future interest to determine whether there is a threshold of METH quantity or a specific drug-experience pattern required to evoke this form of plasticity.

NMDARs are tetramers comprised of two obligatory GluN1 and two regulatory GluN2A or GluN2B subunits. Expression of the GluN2 subunit is developmentally regulated. GluN2B NMDARs are expressed in the developing brain and replaced by GluN2A NMDARs as the brain matures into adulthood (Sheng et al., 1994; Sans et al., 2000). GluN2A and GluN2B NMDARs differ with respect to biophysical properties (Vicini et al., 1998; Erreger et al., 2005; Hansen et al., 2014), synaptic localization (Townsend et al., 2003; Groc et al., 2006), activity-dependent trafficking (Barria and Malinow, 2002), and contributions to synaptic plasticity (Liu et al., 2004; Massey et al., 2004). Since the selective GluN2B blocker did not block the METH SAmediated increases in female NMDA currents or affect their kinetics, we propose that, in contrast to males, in females, METH SA did not change the composition of the NMDAR. Thus, in male rats, METH SA seems to alter NMDAR subunit composition toward an immature state, but in female rats, it does not appear to alter adult NMDAR composition.

While our experiments did not investigate the subunit composition of NMDAR in male and female rats, it is tempting to speculate that since female METH SA rats do not show a strong presence of GluN2B NMDAR, the increase in NMDA current amplitude may be due to the phosphorylation of GluN2A, GluN2C, or GluN2D subunits in the female NMDAR. On the other hand, a study in alcohol-dependent rats has shown that GluN1 subunit protein levels in cerebral cortex increased $144 \pm 12 \%$ compared to control levels in ethanol dependent female, but not male rats (Devaud et al., 1999), thus providing another possible target in the NMDAR that could be modified by METH SA.

The question remains, why does METH SA elicit a significant increase in NMDA currents in female but not male rats? In male rats, it has been shown that cortical activation of AMPAR increases extracellular levels of DA whereas activation of NMDAR decreases it (Jedema and Moghddam, 1996; Takahata and Moghaddam, 1998). These effects are mediated respectively by AMPARs preferentially activating VTA-projecting pyramidal neurons, 
resulting in an excitation of the VTA cells and increases in DA release, and via NMDAR activation of PFC interneurons resulting in inhibition of the cortico-VTA pathway, decreasing DA levels. A recent study has shown that, in contrast to males, activation of NMDAR increases DA levels in females (Locklear et al., 2016). Locklear and colleagues suggest that in females, NMDAR are activating mainly pyramidal neurons projecting to the VTA, thus eliciting an excitation instead of inhibition of VTA cells. The differences in NMDAR activation between male and females may be due to the effects that androgens exert, particularly in the PFC pyramidal cells projecting to the VTA (Aubele and Kritzer, 2012). Building on those findings, it is tempting to speculate that METH elicits an increase in DA release that in turns, in females, acts synergistically with the lack of androgen and results in an enhancement of NMDA currents.

\section{Conclusions}

Our data show that female rats exhibit basic and evoked synaptic cortical differences when compared to males, and we propose that the mechanisms underlying the higher sensitivity of females to METH, as well as the faster acquisition of the drug by females, are mediated by these synaptic differences. We base this suggestion on our results showing that drug-naïve female rats exhibit significant decreases in amplitude and kinetics of sEPSCs compared to male rats but female rats with a history of METH SA exhibit higher amplitude of eEPSCs. Additionally, the GluN2B blocker Ro256981, which decreased NMDA currents in METH SA males, did not affect the NMDA currents in METH SA females. We speculate that the selective effects of METH in female rats may be due to the basal sex differences in the composition and sensitivity of NMDAR located in cortico-VTA projecting neurons.

Our experiments show that there are basal synaptic excitatory differences in PFC of males and female rats and these differences may explain some of the fundamental sex differences in addiction reported in the literature.

\section{References}

Aubele T, Kritzer MF (2012) Androgen influence on prefrontal dopamine systems in adult male rats: localization of cognate intracellular receptors in medial prefrontal projections to the ventral tegmental area and effects of gonadectomy and hormone replacement on glutamate-stimulated extracellular dopamine level. Cereb Cortex 22:1799-1812. CrossRef Medline

Barria A, Malinow R (2002) Subunit-specific NMDA receptor trafficking to synapses. Neuron 35:345-353. CrossRef Medline

Becker JB, Koob GF (2016) Sex differences in animal models: focus on addiction. Pharmacol Rev 68:242-263. CrossRef Medline

Bernheim A, Leong KC, Berini C, Reichel CM (2017) Antagonism of mGlu2/3 receptors in the nucleus accumbens prevents oxytocin from reducing cued methamphetamine seeking in male and female rats. Pharmacol Biochem Behav 161:13-21. CrossRef Medline

Costa RP, Padamsey Z, D'Amour JA, Emptage NJ, Froemke RC, Vogels TP (2017) Synaptic transmission optimization predicts expression loci of long-term plasticity. Neuron 96:177-189.e7. CrossRef Medline

Cox BM, Young AB, See RE, Reichel CM (2013) Sex differences in methamphetamine seeking in rats: impact of oxytocin. Psychoneuroendocrinology 38:2343-2353. CrossRef Medline
Cox BM, Bentzley BS, Regen-Tuero H, See RE, Reichel CM, AstonJones $\mathrm{G}$ (2017) Oxytocin acts in nucleus accumbens to attenuate methamphetamine seeking and demand. Biol Psychiatry 81:949958. CrossRef Medline

Choi S, Lovinger DM (1997) Decreased probability of neurotransmitter release underlies striatal long-term depression and postnatal development of corticostriatal synapses. Proc Natl Acad Sci USA 94:2665-2670. CrossRef Medline

Devaud LL, Matthews DB, Morrow AL (1999) Gender impacts behavioral and neurochemical adaptations in ethanol-dependent rats. Pharmacol Biochem Behav 64:841-849. CrossRef Medline

Dingledine R, Borges K, Bowie D, Traynelis SF (1999) The glutamate receptor ion channels. Pharmacol Rev 51:7-61. Medline

Engelman HS, MacDermott AB (2004) Presynaptic ionotropic receptors and control of transmitter release. Nat Rev Neurosci 5:135145. CrossRef Medline

Erreger K, Dravid SM, Banke TG, Wyllie DJ, Traynelis SF (2005) Subunit-specific gating controls rat NR1/NR2A and NR1/NR2B NMDA channel kinetics and synaptic signalling profiles. J Physiol 563:345-358. CrossRef Medline

Granger AJ, Gray JA, Lu W, Nicoll RA (2011) Genetic analysis of neuronal ionotropic glutamate receptor subunits. J Physiol 589: 4095-4101. CrossRef Medline

Goldstein RZ, Volkow ND (2011) Dysfunction of the prefrontal cortex in addiction: neuroimaging findings and clinical implications. Nat Rev Neurosci 12:652-669. CrossRef Medline

González B, Rivero-Echeto C, Muñiz JA, Cadet JL, García-Rill E, Urbano FJ, Bisagno V (2016) Methamphetamine blunts $\mathrm{Ca}(2+)$ currents and excitatory synaptic transmission through D1/5 receptor-mediated mechanisms in the mouse medial prefrontal cortex. Addict Biol 21:589-602. CrossRef Medline

Groc L, Heine M, Cousins SL, Stephenson FA, Lounis B, Cognet L, Choquet D (2006) NMDA receptor surface mobility depends on NR2A-2B subunits. Proc Natl Acad Sci USA 103:18769-18774. CrossRef Medline

Hansen KB, Ogden KK, Yuan H, Traynelis SF (2014) Distinct functional and pharmacological properties of Triheteromeric GluN1/ GluN2A/GluN2B NMDA receptors. Neuron 81:1084-1096. CrossRef Medline

Jedema HP, Moghddam B (1996) Characterization of excitatory amino acid modulation of dopamine release in the prefrontal cortex of conscious rats. J Neurochem 66:1448-1453. CrossRef Medline

Johansen A, McFadden LM (2017) The neurochemical consequences of methamphetamine self-administration in male and female rats. Drug Alcohol Depend 178:70-74. CrossRef Medline

Keller BU, Konnerth A, Yaari Y (1991) Patch clamp analysis of excitatory synaptic currents in granule cells of rat hippocampus. $J$ Physiol 435:275-293. CrossRef Medline

Li MH, Underhill SM, Reed C, Phillips TJ, Amara SG, Ingram SL (2017) Amphetamine and methamphetamine increase NMDARGluN2B synaptic currents in midbrain dopamine neurons. Neuropsychopharmacology 42:1539-1547. CrossRef Medline

Liu L, Wong TP, Pozza MF, Lingenhoehl K, Wang Y, Sheng M, Auberson YP, Wang YT (2004) Role of NMDA receptor subtypes in governing the direction of hippocampal synaptic plasticity. Science 304:1021-1024. CrossRef Medline

Locklear MN, Cohen AB, Jone A, Kritzer MF (2016) Sex differences distinguish intracortical glutamate receptor-mediated regulation of extracellular dopamine levels in the prefrontal cortex of adult rats. Cereb Cortex 26:599-610. CrossRef Medline

Luthi A, Lsucher C (2014) Pathological Ccirucit fucntiion underlying addiciiton and anxiety disorders Nat. Neurosci 17:1635-1643. CrossRef Medline

Massey PV, Johnson BE, Moult PR, Auberson YP, Brown MW, Molnar E, Collingridge GL, Bashir ZI (2004) Differential roles of NR2A and NR2B-containing NMDA receptors in cortical long-term potentiation and long-term depression. J Neurosci 24:7821-7828. CrossRef Medline 
Milesi-Hallé A, McMillan DE, Laurenzana EM, Byrnes-Blake KA, Owens SM (2007) Sex differences in (+)-amphetamine- and (+)methamphetamine-induced behavioral response in male and female Sprague-Dawley rats. Pharmacol Biochem Behav 86:140149. CrossRef Medline

Milesi-Hallé A, Hambuchen MD, McMillan DE, Owens SM (2015) The pharmacokinetics of methamphetamine self-administration in male and female rats. Drug Alcohol Depend 150:164-169. CrossRef Medline

Mishra D, Pena-Bravo Jl, Leong KC, Lavin A, Reichel CM (2017) Methamphetamine self-administration modulates glutamate neurophysiology. Brain Struct Funct 222:2031-2039. CrossRef Medline

Monyer H, Sprengel R, Schoepfer R, Herb A, Higuchi M, Lomeli H, Burnashev N, Sakmann B, Seeburg PH (1992) Heteromeric NMDA receptors: molecular and functional distinction of subtypes. Science 256:1217-1221. CrossRef Medline

Parsegian A, Glen WB Jr, Lavin A, See RE (2011) Methamphetamine self-administration produces attentional set-shifting deficits and alters prefrontal cortical neurophysiology in rats. Biol Psychiatry 69:253-259. CrossRef Medline

Reichel CM, Chan CH, Ghee SM, See RE (2012) Sex differences in escalation of methamphetamine self-administration: cognitive and motivational consequences in rats. Psychopharmacology (Berl) 223:371-380. CrossRef Medline

Roth ME, Carroll ME (2004) Sex differences in the acquisition of IV methamphetamine self-administration and subsequent maintenance under a progressive ratio schedule in rats. Psychopharmacology (Berl) 172:443-449. CrossRef Medline

Ruda-Kucerova J, Amchova P, Babinska Z, Dusek L, Micale V, Sulcova A (2015) Sex differences in the reinstatement of methamphetamine seeking after forced abstinence in Sprague-Dawley rats. Front Psychiatry 6:91. CrossRef Medline

Sans N, Petralia RS, Wang YX, Blahos J 2nd, Hell JW, Wenthold RJ (2000) A developmental change in NMDA receptor-associated proteins at hippocampal synapses. J Neurosci 20:1260-1271. CrossRef Medline

Sheng M, Cummings J, Roldan LA, Jan YN, Jan LY (1994) Changing subunit composition of heteromeric NMDA receptors during development of rat cortex. Nature 368:144-147. CrossRef Medline

Stincic TL, Frerking ME (2015) Different AMPA receptor subtypes mediate the distinct kinetic components of a biphasic EPSC in hippocampal interneurons. Front Synaptic Neurosci 7:7. CrossRef Medline

Takahata R, Moghaddam B (1998) Glutamatergic regulation of basal and stimulus-activated dopamine release in the prefrontal cortex. $\mathrm{J}$ Neurochem 71:1443-1449. CrossRef Medline

Townsend M, Yoshii A, Mishina M, Constantine-Paton M (2003) Developmental loss of miniature $\mathrm{N}$-methyl-D-aspartate receptor currents in NR2A knockout mice. Proc Natl Acad Sci USA 100: 1340-1345. CrossRef Medline

Tomita S (2010) Regulation of ionotropic glutamate receptors by their auxiliary subunits. Physiology (Bethesda) 25:41-49. CrossRef Medline

UNODC (2017) World Drug Report. United Nations Office on Drugs and Crime. Available at https://www.unodc.org/wdr2017/field/ WDR_2017_presentation_lauch_version.pdf

Venniro M, Zhang M, Shaham Y, Caprioli D (2017) Incubation of methamphetamine but not heroin craving after voluntary abstinence in male and female rats. Neuropsychopharmacology 42: 1126-1135. CrossRef Medline

Vicini S, Wang JF, Li JH, Zhu WJ, Wang YH, Luo JH, Wolfe BB, Grayson DR (1998) Functional and pharmacological differences between recombinant N-methyl-D-aspartate receptors. J Neurophysiol 79:555-566. CrossRef Medline

Wyllie DJ, Béhé P, Colquhoun D (1998) Single-channel activations and concentration jumps: comparison of recombinant NR1a/NR2A and NR1a/NR2D NMDA receptors. J Physiol 510:1-18. CrossRef

Yuan H, Hansen KB, Vance KM, Ogden KK, Traynelis SF (2009) Control of NMDA receptor function by the NR2 subunit aminoterminal domain. J Neurosci 29:12045-12058. CrossRef Medline 